\title{
EFFECTIVENESS OF TICAGRELOR COMPARED TO CLOPIDOGREL IN REDUCING THE RISK OF MAJOR ADVERSE CARDIOVASCULAR EVENTS IN PATIENTS WITH CORONARY HEART DISEASE AFTER PERCUTANEOUS CORONARY INTERVENTION
}

\author{
HENDRA WANA NUR'AMINa, IWAN DWIPRAHAST0b, ERNA KRISTIN ${ }^{b}$ \\ aDepartment of Pharmacology and Therapy, Faculty of Medicine, Universitas Lambung Mangkurat, bDepartment of Pharmacology and \\ Therapy Faculty of Medicine, Universitas Gadjah Mada \\ Email: hendranuramin@gmail.com
}

Received: 17 Jun 2017 Revised and Accepted: 22 Jul 2017

\begin{abstract}
Objective: Antiplatelet therapy is recommended in patients with coronary heart disease (CHD) who had the percutaneous coronary intervention (PCI) procedure to reduce major adverse cardiovascular events (MACE). There has been a lack of population-based studies that showed the superior effectiveness of ticagrelor over clopidogrel and similar studies have not been conducted in Indonesia yet. The aim of the study was to investigate the effectiveness of ticagrelor compared to clopidogrel in reducing the risk of MACE in patients with CHD after PCI.
\end{abstract}

Methods: A retrospective cohort study with 1-year follow-up was conducted. 361 patients consisted of 111 patients with ticagrelor exposure and 250 patients with clopidogrel exposure. The primary outcome was MACE, defined as a composite of repeat revascularization, myocardial infarction, or all-cause death. The association between antiplatelet exposure and the MACE was analyzed with Cox proportional hazard regression, adjusted for sex, age, comorbid, PCI procedures and concomitant therapy.

Results: MACE occurred in $22.7 \%$ of the subjects. Clopidogrel had a significantly higher risk of MACE compared with ticagrelor $(28.8 \%$, vs $9.0 \%$, hazard ratio (HR): 1.96 (95\% CI 1.01 to 3.81, $\mathrm{p}=0.047)$. There were no significant differences in risk of repeat revascularization $(20.40 \%$ vs $5.40 \%$, HR: $2.32,95 \%$ CI 0.99 to $5.42, p=0.05)$, myocardial infarction ( $11.60 \%$ vs $3.60 \%$, HR: $2.08,95 \%$ CI, 0.73 to $5.93, p=0.17)$, and death (1.60\% vs $1.80 \%$, HR: $0.77,95 \%$ CI, 0.14 to $4.25, \mathrm{p}=0.77$ ).

Conclusion: Clopidogrel had a higher risk of MACE compared to clopidogrel in patients with CHD after PCI, but there were no significant differences in the risk of repeat revascularization, myocardial infarction, and all-cause death.

Keywords: Ticagrelor, Clopidogrel, Percutaneous coronary intervention, Major adverse cardiovascular events

(C) 2017 The Authors. Published by Innovare Academic Sciences Pvt Ltd. This is an open access article under the CC BY license (http://creativecommons.org/licenses/by/4.0/) DOI: http://dx.doi.org/10.22159/ijpps.2017v9i9.20361

\section{INTRODUCTION}

Coronary heart disease (CHD) is a global health problem that leads to impaired quality of life and shortens life expectancy $[1,2]$. Current guidelines from the American College of Cardiology and American Heart Association (ACC/AHA) recommend percutaneous coronary intervention (PCI) and antiplatelet therapy with aspirin and $\mathrm{P}_{12}$ receptor inhibitors (clopidogrel and ticagrelor) to support reperfusion after PCI [3]. Guidelines recommend the use of aspirin indefinitely, clopidogrel and ticagrelor are recommended until 1 y $[4,5]$.

Antiplatelet drugs can prevent the occurrence of major adverse cardiovascular events (MACE) in patients with CHD [6,7]. MACE is defined as a composite event of repeat coronary revascularization, myocardial infarction, and all-cause death $[8,9]$.

Indonesia has different population and CHD risk factors from other countries. The main risk factors for CHD such as diabetes mellitus (DM), hypertension, dyslipidemia, and smoking are found in great quantities $[10,11]$. In addition, research on the effectiveness of ticagrelor which is a relatively new drug in real conditions on the population has never been done in Indonesia. Therefore, it is necessary to investigate on ticagrelor compared with clopidogrel therapy against the MACE in patients with CHD after PCI with a retrospective cohort study design. This research was conducted at the National Cardiovascular Center Harapan Kita Hospital which is the national referral for cardiovascular disease in Indonesia [12].

\section{MATERIALS AND METHODS}

This study was an observational study with a retrospective cohort design to investigate the effectiveness of ticagrelor compared with clopidogrel therapy in preventing MACE in patients with CHD after PCI. The population was patients with CHD after PCI who have got dual antiplatelet therapy and recorded in the medical records. Medical records were selected and then categorized based on the exposure status of ticagrelor and clopidogrel. MACE events were followed by the medical records.

Inclusion criteria in this study were age $>18 \mathrm{y}$, diagnosed with CHD, got PCI procedure and got dual antiplatelet. While exclusion criteria were patients with antiplatelet therapy without AHA guidelines or the data of medical records were not available for research. This study collected all patients receiving ticagrelor with appropriate inclusion and exclusion criteria then compared with patients receiving clopidogrel therapy as a comparison (control).

The dependent variables in this study were MACE defined as a composite event of repeat revascularization, myocardial infarction, and death. Repeat revascularization was defined as a procedure of PCI or coronary artery bypass graft (CABG) performed on coronary arteries that have been treated or not treated at the time of PCI, which was considered as the beginning of the study [8,13]. Myocardial infarction is a disorder that consists of non-ST elevation acute coronary syndrome (NSTE-ACS) and ST-elevation myocardial infarction (STEMI) [14].

Death in this study was all deaths from various causes that occurred during the observation in medical record [15]. The independent variables in this study were ticagrelor therapy with $2 \times 90 \mathrm{mg}$ dose and clopidogrel therapy at a dose of $1 \times 75 \mathrm{mg}$. Other variables that affect this study were gender, age, PCI (indication PCI, urgency, type of stent, number of stents), comorbidities (diabetes, hypertension, dyslipidemia, heart failure, stroke, chronic kidney disease, compliance, smoking), and concomitant therapy (antihypertensive, 
anti-dyslipidemia, anti-diabetic, anticoagulant, proton pump inhibitor).

The collected data were tabulated. Continuous variables were presented as mean $\pm \mathrm{SD}$, whereas categorical variables were presented as a proportion (\%). We used SPSS 20.0 for data analysis. Baseline characteristics of the patients were analyzed using chi-square or Fisher exact and t-test. Multivariable analysis was performed by logistic regression and Cox regression multi variable to examine the relationship between independent variables with MACE dependent variable, adjusted for the significant variables $(\mathrm{p}<0.05)$. This study was approved by the ethics committee of the Faculty of Medicine, Gadjah Mada University, Yogyakarta (ethical approval Ref: KE/FK/309/ EC/2015) and National Cardiovascular Center Harapan Kita Hospital ethics committee (ethical approval No.: LB.02.01/VII/059/KEP.022 EV/2015).

\section{RESULTS}

In this study, we found 361 subjects consisted of 111 patients with ticagrelor and 250 patients with clopidogrel. Mean follow-up was $152.87+139.45 \mathrm{~d}$ with the median follow-up $112 \mathrm{~d}$. Baseline characteristics of the subjects can be seen in table 1 .

Table 1: Baseline characteristics of subjects by sex, age, PCI and comorbid

\begin{tabular}{|c|c|c|c|c|c|}
\hline \multirow[b]{2}{*}{ Patients (n) } & \multicolumn{2}{|c|}{ Ticagrelor (\%) } & \multicolumn{2}{|c|}{ Clopidogrel (\%) } & \multirow[t]{2}{*}{$\mathbf{p}$} \\
\hline & 111 & $(100)$ & 250 & $(100)$ & \\
\hline \multicolumn{6}{|l|}{ Gender } \\
\hline Male & 103 & $(92.8)$ & 232 & $(92.8)$ & 0.99 \\
\hline \multicolumn{6}{|l|}{ Age category } \\
\hline$<65 y$ & 89 & $(80.2)$ & 198 & $(79.2)$ & 0.83 \\
\hline Mean (SD) & 55.79 & +12.73 & 55.93 & +11.01 & 0.49 \\
\hline \multicolumn{6}{|l|}{ PCI } \\
\hline \multicolumn{6}{|l|}{ Indication of PCI } \\
\hline ACS & 59 & $(53.2)$ & 123 & $(49.2)$ & 0,49 \\
\hline CHD & 52 & $(46.8)$ & 127 & $(50.8)$ & \\
\hline \multicolumn{6}{|l|}{ Urgency } \\
\hline Elective & 65 & $(58.6)$ & 150 & $(60)$ & 0.80 \\
\hline Primary/Early PCI & 46 & $(41.4)$ & 100 & $(40)$ & \\
\hline History of Coronary Intervention & 22 & (19.8) & 14 & $(4,8)$ & $<0.001$ \\
\hline \multicolumn{6}{|l|}{ Stent Type } \\
\hline Without stent & 9 & $(8,1)$ & 7 & $(2,8)$ & 0.05 \\
\hline BMS & 7 & $(6,3)$ & 43 & $(17.2)$ & 0.01 \\
\hline DES & 95 & $(85.6)$ & 200 & $(85.6)$ & $\mathrm{REF}$ \\
\hline \multicolumn{6}{|l|}{ Number of Stent } \\
\hline $0-2$ & 47 & $(25.7)$ & 136 & $(74.3)$ & 0,03 \\
\hline $3-4$ & 64 & $(36.0)$ & 114 & $(64.0)$ & REF \\
\hline Mean (SD) & 1.77 & +1.02 & 1.56 & +0.81 & 0,04 \\
\hline \multicolumn{6}{|l|}{ Comorbid } \\
\hline Diabetes mellitus & 45 & $(40.5)$ & 104 & $(41.6)$ & 0.85 \\
\hline Hypertension & 65 & $(58.6)$ & 151 & $(60.4)$ & 0.74 \\
\hline Heart failure & 23 & (20.7) & 68 & $(27.2)$ & 0.19 \\
\hline Dyslipidemia & 38 & $(34.2)$ & 84 & $(33.6)$ & 0,91 \\
\hline Chronic Kidney Disease & 7 & $(6,3)$ & 22 & $(8,8)$ & 0.42 \\
\hline Medication Compliance & 9 & $(8,1)$ & 14 & $(5,6)$ & 0.38 \\
\hline Smoke & 40 & $(36.0)$ & 110 & $(43.6)$ & 0.18 \\
\hline \multicolumn{6}{|l|}{ Concurrent therapy } \\
\hline Diuretics & 32 & $(28.8)$ & 88 & $(35.2)$ & 0.24 \\
\hline Beta Blocker & 81 & $(73.0)$ & 195 & $(78.0)$ & 0.30 \\
\hline ACE Inhibitors & 44 & (39.7) & 143 & $(57.2)$ & 0.00 \\
\hline Angiotensin Receptor Blockers (ARB) & 37 & (33.3) & 53 & $(21.2)$ & 0.01 \\
\hline Calcium Channel Blockers & 20 & $(18.0)$ & 53 & $(21.2)$ & 0.49 \\
\hline Insulin & 14 & $(12.6)$ & 37 & (14.8) & 0.58 \\
\hline Biguanide & 26 & $(23.4)$ & 58 & $(23.2)$ & 0.96 \\
\hline Sulfonylurea & 8 & $(7,2)$ & 27 & $(10.8)$ & 0.29 \\
\hline DPP-4 inhibitors & 7 & $(6,3)$ & 7 & $(2,8)$ & 0.14 \\
\hline Oral anticoagulant & 1 & $(0,9)$ & 7 & $(2,8)$ & 0.15 \\
\hline Proton Pump Inhibitor & 10 & $(9.0)$ & 19 & (7.6) & 0.65 \\
\hline
\end{tabular}

Table 2: Predictor factors of MACE in CHD patients with PCI

\begin{tabular}{|c|c|c|c|c|}
\hline \multirow[t]{2}{*}{ Predictor factors of MACE } & \multicolumn{2}{|l|}{ Unadjusted } & \multicolumn{2}{|l|}{ Adjusted } \\
\hline & OR (95\% CI) & $\mathbf{p}$ & OR (95\% CI) & $\mathbf{p}$ \\
\hline \multicolumn{5}{|l|}{ Antiplatelet } \\
\hline Clopidogrel & $4.09(2.02-8.27)$ & $<0.001$ & $3.62(1.77-7.42)$ & $<0.001$ \\
\hline \multicolumn{5}{|l|}{ Ticagrelor } \\
\hline \multicolumn{5}{|l|}{ Hypertension } \\
\hline Yes & $1.72(1.02-2.91)$ & 0.04 & $1.76(1.02-3.04)$ & 0,04 \\
\hline \multicolumn{5}{|l|}{ No } \\
\hline \multicolumn{5}{|l|}{ Heart failure } \\
\hline Yes & $1.78(1.04-3.04)$ & 0.03 & $1.70(0.97-2.97)$ & 0.06 \\
\hline \multicolumn{5}{|l|}{ No } \\
\hline \multicolumn{5}{|l|}{ ACE Inhibitors } \\
\hline No & $0.47(0.28-0.79)$ & 0.004 & $0.54(0.32-0.92)$ & 0,02 \\
\hline Yes & & & & \\
\hline
\end{tabular}


Based on bivariate analysis, the significant predictor factors of MACE presented in table 2 were antiplatelet, hypertension, heart failure, and ACE inhibitor. Multivariable logistic regression analysis showed that the significant predictor factors of MACE were the type of antiplatelet, ACE inhibitor and hypertension. This suggested that clopidogrel had a higher risk compared to ticagrelor.

The predictor factors of repeat revascularization based on bivariate analysis were the type of antiplatelet drugs, ACE inhibitors, and
ARB. To investigate which factor with the most contribution, multivariable logistic regression were performed.

The significant predictor factors were antiplatelet (OR: $3.9495 \%$ CI 1.62 to 9.56) and ACE inhibitor (OR: $2.4395 \%$ CI from 1.29 to $4.56, p=0.006)$. ARB did not affect the incidence of repeat revascularization procedures significantly. Predictor factors of repeat revascularization procedures in CHD patients with PCI can be seen in table 3 .

Table 3: Predictor factors of repeat revascularization in CHD patients with PCI

\begin{tabular}{|c|c|c|c|c|}
\hline \multirow[t]{2}{*}{ Repeat revascularization procedure factor predictors } & \multicolumn{2}{|l|}{ Unadjusted } & \multicolumn{2}{|l|}{ Adjusted } \\
\hline & OR (95\% CI) & $\mathbf{p}$ & OR (95\% CI) & $\mathbf{p}$ \\
\hline \multicolumn{5}{|l|}{ Antiplatelet } \\
\hline Clopidogrel & $4.49(1.86-10.80)$ & $<0.001$ & $3.94(1.62-9.56)$ & 0.002 \\
\hline \multicolumn{5}{|l|}{ Ticagrelor } \\
\hline \multicolumn{5}{|l|}{ ACE Inhibitors } \\
\hline No & $2.77(1.49-5.15)$ & 0.001 & $2.23(1.08-4.79)$ & 0.03 \\
\hline \multicolumn{5}{|l|}{ Yes } \\
\hline \multicolumn{5}{|l|}{ Angiotensin Receptor Blocker } \\
\hline No & $2.26(1.03-4.98)$ & 0.04 & $1.16(0.44-3.00)$ & 0.76 \\
\hline Yes & & & & \\
\hline
\end{tabular}

The significant predictor factor of myocardial infarction based on logistic regression analysis was the type of antiplatelet (OR: 3.51, $95 \%$ CI 1.20 to $10.24, p=0.015$ ) which showed that clopidogrel had a higher risk of myocardial infarction compared to ticagrelor.
The significant predictor factor of mortality based on logistic regression analysis was the beta blocker therapy (OR: $0.89,95 \% \mathrm{CI}$ 0.16 to 4.91 ) indicating that beta-blocker therapy had a lower risk for death.

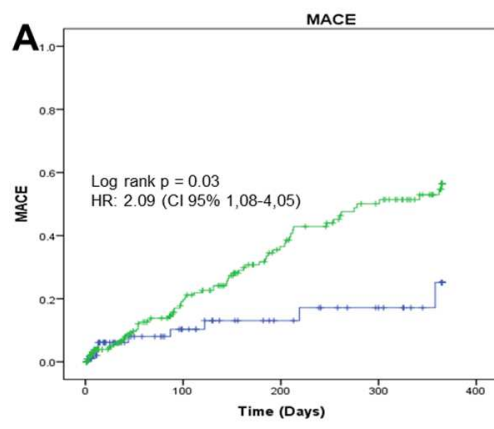

Kaplan-Meiercurve for MACE

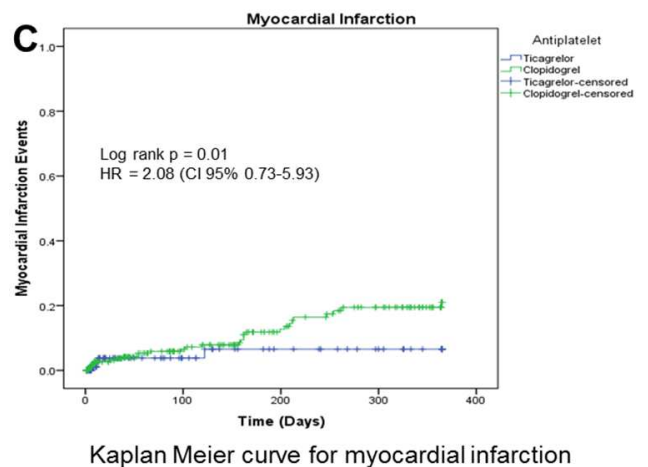

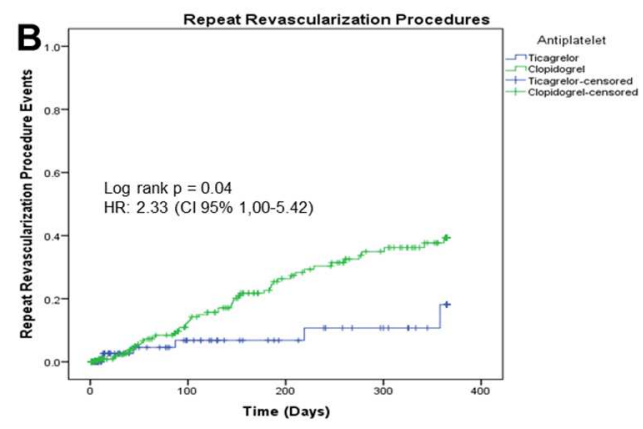

Kaplan Meier curve for repeat revascularization

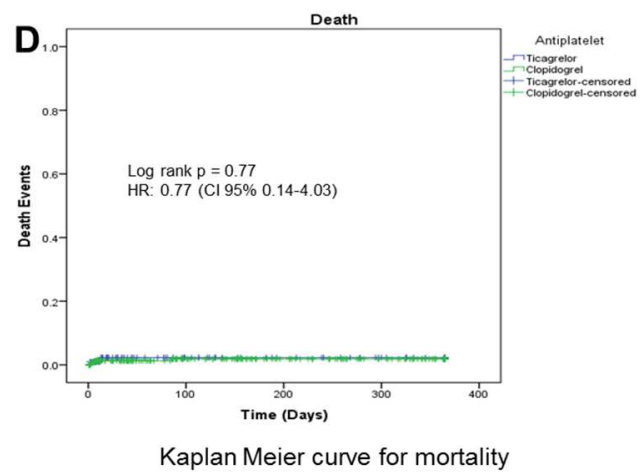

Fig. 1: A kaplan-meier curve for MACE. B, kaplan-meier curve for repeat revascularization procedures. C, kaplan-meier curve for myocardial infarction. D, kaplan-meier curve for mortality

Analysis of MACE survival at $1 \mathrm{y}$ follow-up showed that clopidogrel had higher risk of MACE significantly with HR 2.09 (95\% CI, 1.08 to $4.05, \mathrm{p}=0.03)$ and patients with ACE inhibitors had a significantly higher risk of MACE with HR 1.66 (95\% CI,1.05 to 2.62, p = 0.03). Multivariable Cox regression analysis indicated factor that affects the MACE was antiplatelet HR 1.96 (95\% CI 1.01 to 3.81, $\mathrm{p}=0.047)$ while ACE inhibitors HR 1.58 (95\% CI 0.99 to 2.49 , $\mathrm{p}=$ 0.05 ) did not affect the incidence of MACE significantly after adjustment analysis.

Clopidogrel had a higher risk of MACE compared to ticagrelor mainly due to the number of repeated revascularization in the clopidogrel group. 
Repeat revascularization procedures with $1 \mathrm{y}$ follow-up showed that ACE inhibitor therapy had a higher risk of repeat revascularization procedures significantly with $\mathrm{HR} 2.14(95 \% \mathrm{CI}$, 1.20 to 3.82, $\mathrm{p}=0.01$ ) while clopidogrel had a higher risk of repeat revascularization procedures compared to ticagrelor but not significant with HR 2.33 (95\% CI, 0.99 to 5.42, p = 0.05). Analysis of survival in myocardial infarction showed that clopidogrel drugs had a higher risk of myocardial infarction but not significant with HR 2, 08 (95\% CI, 0.73 to 5.93, p = 0.172) compared to ticagrelor. Analysis of survival to the death during the first year showed that beta-blocker can reduce the risk of death $(\mathrm{p}<0.05)$, HR 0.827 ( $95 \%$ CI 0.70 to $0.98, p=0.03$ ). Antiplatelet effectiveness on MACE, repeat revascularization procedures, myocardial infarction and death can be seen in table 4 .

Table 4: Analysis of survival on MACE, repeat revascularization procedures, myocardial infarction, and death based on the type of antiplatelet

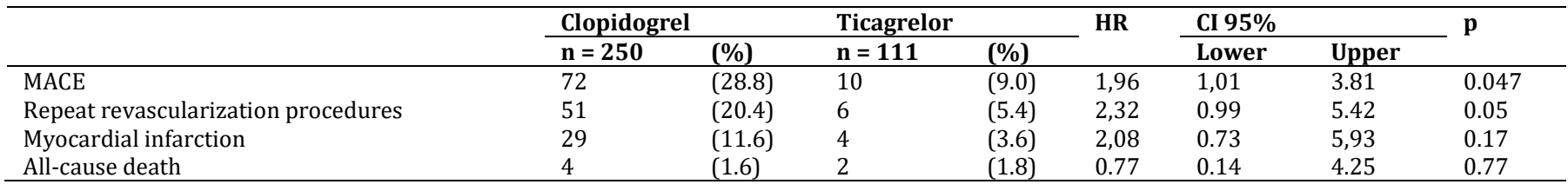

\section{DISCUSSION}

Platelets play important role in arterial thrombosis, leading to myocardial infarction [20]. Antiplatelet such as aspirin, clopidogrel, and ticagrelor are recommended to prevent thrombosis for patients with CHD with or without PCI.Clopidogrel is a pro-drug that requires metabolism primarily by CYP450 enzymes to become active metabolite [21, 22]. The molecular target of the clopidogrel active metabolite is responsible for triggering platelet aggregation. The active metabolite works by forming an irreversible covalent bond with receptors $\mathrm{P}_{2} \mathrm{Y}_{12}$. Along these covalent bonds, ADP cannot bind to receptors $\mathrm{P}_{2} \mathrm{Y}_{12}$ [23]. Clopidogrel has different responses that lead to inhibition of platelet aggregation be affected [24]. The different responses are caused by the polymorphism of enzyme CYP2C19profile [25, 26,]

Ticagrelor is a new antiplatelet agent that do not require metabolism to perform its activities. Ticagrelor mechanism with $\mathrm{P}_{2} \mathrm{Y}_{12}$ receptor binding in a different place with its predecessor; clopidogrel or prasugrel so that ADP receptor is inactivated without first metabolized into the active metabolite. The bonding that occurs between ticagrelor and the $\mathrm{P}_{2} \mathrm{Y}_{12}$ receptor is the hydrogen bond that weaker than covalent so that the bond is reversible. This causes ticagrelor has a faster duration of action [27, 28]. Differences in the characteristics of both antiplatelet can play a role in reducing the incidence of thrombosis which can lead to the need for repeat revascularization procedures, myocardial infarction, and death in patients with CHD [29]. In addition to these effects, delayed onset and the poor inhibition of platelet and adherence to dual antiplatelet therapy may increase the risk of stent thrombosis [6].

This study aimed to compare the effectiveness of ticagrelor compared to clopidogrel in the MACE in CHD patients after PCI. The MACE survival analysis results showed that clopidogrel had a higher risk of MACE compared to ticagrelor. It was similar to the study from Lindholm et al., (2014) in patients with NSTE-ACS; the primary end point was better on ticagrelor compared to clopidogrel $(10.0 \%$ vs. $12.3 \%$, HR 0.83, CI 95\% 0, 74-.93) [30]. However, this study differed from other studies such as Steg et al., (2010) and Kang et al., (2015) [31, 32]. According to Steg et al., (2010) ticagrelor compared to clopidogrel therapy did not differ significantly in preventing the primary endpoint in patients with STEMI with PCI HR 0.87 (95\% CI, 0.75 to $1.01, \mathrm{p}=0.07$ ) [31], while study from Kang et al., (2015) showed us that ticagrelor therapy was not significantly different than clopidogrel in preventing the primary endpoint in patients who have CHD in Asia population [32]. This could be due to differences in the characteristics of the subject, method, sample size, type of disease and some possible causes that could affect the results.

In this study, repeated revascularization was not significantly affected by antiplatelet. The variable that influenced the repeat revascularization procedure was ACE inhibitor. The ACE inhibitor can lower the risk of cardiovascular events [19], but the analysis of survival in this study showed it had a higher risk of repeat revascularization procedure significantly. This was likely due to comorbidities, characteristics of the subject, study design, sample size, disease and others.

Analysis of survival with one-year follow-up in myocardial infarction indicated that the clopidogrel had a higher risk of myocardial infarction but not significant with HR 2,08 (95\% CI, 0.73 to 5.93, p = 0.172) compared to ticagrelor. Study from Steg et al., (2010) showed that ticagrelor was better significantly in preventing myocardial infarction in PCI patients with STEMI (ticagrelor $4.7 \%$ vs clopidogrel $5.8 \%$, HR $0.8095 \%$ CI 0.65 to $0.98, p=0.03$ ) [31]. A study from Lindholm et al., (2014) in patients with NSTE-ACS stated that prevention of myocardial infarction was better on ticagrelor compared to clopidogrel with HR of 0.86 (95\% CI 0.74 to 0.99 ) [30]. While Kang et al., (2015) showed ticagrelor therapy was not significantly different than clopidogrel in preventing myocardial infarction in Asian patients who have CHD (HR 0.83, 95\% CI 0.59 to 1.16) [32]. Analysis of survival in death for $1 \mathrm{y}$ showed that betablocker therapy can reduce the risk of death. This was consistent with other research that concluded in patients with CHD who underwent noncardiac surgery, beta-blockers can reduce the incidence of death and MACE significantly, especially in patients who have recently experienced a myocardial infarction and patients with heart failure [33]. Beta-blocker therapy in heart failure patients also proven to reduce the risk of sudden death from a cardiovascular event by $31 \%, 29 \%$ cardiovascular death and death from all causes by $33 \%[34]$.

Univariate Cox regression analysis showed that clopidogrel had a lower risk of death compared to ticagrelor but insignificant with HR 0.77 (95\% CI, 0.14 to $4.25, \mathrm{p}=0.77$ ). Steg et al., (2010) found that ticagrelor therapy did not differ significantly in preventing death in patients with STEMI (5.0\% ticagrelor vs clopidogrel $6.1 \%$, HR 0.80 $95 \%$ CI 0.67 to $1.00 \mathrm{p}=0.05$ ) [30]. Lindholm et al., (2014) showed that in patients with NSTE-ACS, the death incidence was better on ticagrelor compared to clopidogrel (4.3\% vs 5.8\%, HR 0.76, 95\% CI 0.64 to 0.90 ) [31]. Kang et al., (2015) indicated that ticagrelor therapy was not significantly different than clopidogrel in preventing death in Asian patients who have CHD (HR 0.77, 95\% CI 0.51 to 1.17 ) [32].

This research had some limitations because of some factors; single centre study, retrospective cohort design, different MACE definition, data registry of drug use and prescribing, and diseases such as CHD, myocardial infarction, and death were not documented well in Indonesia. To solve the limitations, we used survival analysis. The data would be censored if there were discontinuation of therapy, replacement therapy, loss to follow-up or cardiovascular events such as repeat revascularization procedure, myocardial infarction, and death.

Although this research still had some limitations, this study was expected to be the foundation for conducting further study to investigate the effectiveness of available antiplatelet in Indonesia to investigate the MACE with a higher level of evidence and include drug safety profile. Furthermore, other variables can be investigated 
such as the characteristic of the subjects (e. g., ethnicity, nutritional status), other comorbidities, laboratory data, procedures, concomitant therapy and much more.

\section{CONCLUSION}

We concluded that clopidogrel therapy had a significantly greater risk of MACE compared with ticagrelor in CHD patients with 1-year follow-up after PCI. However, there was no significant difference between ticagrelor and clopidogrel on the risk of repeat revascularization, myocardial infarction, and death.

\section{ACKNOWLEDGMENT}

We would like to thank Harapan Kita National Cardiovascular Center Hospital Jakarta, Ministry of Research, Technology and Higher Education of the Republic of Indonesia and all people for their excellent assistance with data collection and analysis.

\section{AUTHOR CONTRIBUTION}

Hendra Wana Nur'amin planned the study, collected the data and wrote the manuscript. Iwan Dwiprahasto planned the study, conducted the analyses, and agreed on the final version of the manuscript. Erna Kristin planned the study, conducted the analyses, edited the manuscript and agreed on the final version of the manuscript.

\section{CONFLICT OF INTERESTS}

The authors have no conflict of interest

\section{REFERENCES}

1. Wong ND. Epidemiological studies of CHD and the evolution of preventive cardiology. Nat Rev Cardiol 2014;11:276-89.

2. Mendis S, Thygesen K, Kuulasmaa K, Giamsssspaoli S, Mahonen $\mathrm{M}$, Blackett KN, et al. World health organization definition of myocardial infarction: 2008-09 revision. Int J Epidemiol 2011;40:139-46.

3. Levine GN, Bates ER, Blankenship JC, Bailey SR, Bittl JA, Cercek $\mathrm{B}$, et al. ACCF/AHA/SCAI guideline for percutaneous coronary intervention. J Am Coll Cardiol 2011;58:81.

4. O'Gara PT, Kushner FG, Ascheim DD, Casey DE, Mina K, Lemos JA De, et al. Foundation/American heart association task force on practice guidelines ACCF/AHA guideline 2013 ACCF/AHA guideline for the management of ST-elevation myocardial infarction: executive summary a report of the american college of cardiology foundation. Circulation 2013;127:529-55.

5. Amsterdam Ea, Wenger NK, Brindis RG, Casey DE, Ganiats TG, Holmes DR, et al. 2014 AHA/ACC guideline for the management of patients with non-ST-elevation acute coronary syndromes. J Am Coll Cardiol 2014;64:e139-228.

6. Wallentin L. P2Y12 inhibitors: differences in properties and mechanisms of action and potential consequences for clinical use. Eur Heart J 2009;30:1964-77.

7. Zhou YH, Wei X, Lu J, Ye XF, Wu MJ, Xu JF, et al. Effects of combined aspirin and clopidogrel therapy on cardiovascular outcomes: a systematic review and meta-analysis. PLoS One 2012; 7:e31642.

8. Song PS, Kim DK, Seo GW, Kim KH, Seol SH, Yang JH, et al. Spironolactone lowers the rate of repeat revascularization in acute myocardial infarction patients treated with percutaneous coronary intervention. Am Heart J Mosby Inc 2014;168:346-53 e3.

9. Meliga E, Fiorina C, Valgimigli M, Belli R, Gagnor A, Sheiban I, et al. Early angio-guided complete revascularization versus culprit vessel PCI followed by ischemia-guided staged PCI in STEMI patients with multivessel disease. J Interv Cardiol 2011;24:535-41.

10. Juwana YB, Wirianta J, Ottervanger JP, Dambrink JHE, Van't Hof AWJ, Gosselink TM, et al. Primary coronary intervention for STelevation myocardial infarction in Indonesia and the Netherlands: a comparison. Netherlands Hear J 2009;17:418-21.

11. Ueshima H, Sekikawa A, Miura K, Turin TC, Takashima N, Kita $\mathrm{Y}$, et al. Cardiovascular disease and risk factors in asia: a selected review. Circulation 2008;118:2702-9.
12. Dharma S, Juzar DA, Firdaus I, Soerianata S, Wardeh AJ, Jukema JW. Acute myocardial infarction system of care in the third world. Netherlands Hear J 2012;20:254-9.

13. Alhejily WA, Ohman EM. Repeat revascularization after PCI: are we reinventing the wheel or redefining achilles' heel? Circ Cardiovasc Interv 2012;5:746-7.

14. Thygesen K, Alpert JS, Jaffe AS, Simoons ML, Chaitman BR, White HD, et al. Third universal definition of myocardial infarction. J Am Coll Cardiol 2012;60:1581-98.

15. Cannon CP, Brindis RG, Chaitman BR, Cohen DJ, Cross JT, Drozda JP, et al. ACCF/AHA key data elements and definitions for measuring the clinical management and outcomes of patients with acute coronary syndromes and coronary artery disease: a report of the American college of cardiology foundation/American heart association. Circulation 2013;127:1052-89.

16. Leander K, Wiman B, Hallqvist J, Andersson T, Ahlbom A, de Faire U. Primary risk factors influence risk of recurrent myocardial infarction/death from coronary heart disease: results from the stockholm heart epidemiology program (SHEEP). Eur J Cardiovasc Prev Rehabil 2007;14:532-7.

17. Picariello $\mathrm{C}$, Lazzeri $\mathrm{C}$, Attanà $\mathrm{P}, \mathrm{Chiostri} \mathrm{M}$, Gensini GF, Valente S. The impact of hypertension on patients with acute coronary syndromes. Int J Hypertens 2011. http://dx.doi.org/ $10.4061 / 2011 / 563657$

18. Lee MG, Jeong MH, Lee KH, Park KH, Sim DS, Yoon HJ, et al. Prognostic impact of diabetes mellitus and hypertension for the mid-term outcome of patients with acute myocardial infarction who underwent percutaneous coronary intervention. J Cardiol Jpn College Cardiol 2012;60:257-63.

19. Law MR, Morris JK, Wald NJ. Use of blood pressure lowering drugs in the prevention of cardiovascular disease: a metaanalysis of 147 randomised trials in the context of expectations from prospective epidemiological studies. Be Med J 2009;338:b1665.

20. Kumar S. Dental management of patients on antiplatelet therapy: literature update. Asian J Pharm Clin Res 2016;9:26-31.

21. Schroeder WS, Ghobrial L, Gandhi PJ. Possible mechanisms of drug-induced aspirin and clopidogrel resistance. J Thromb Thrombolysis 2006;22:139-50.

22. Bashir S, Poornima R. Pharmacogenetic variations related to clopidogrel resistance and its clinical implications: an issue which remains largely unaddressed. Asian J Pharm Clin Res 2016;9:12-4.

23. Dobesh PP, Oestreich JH. Ticagrelor: pharmacokinetics, pharmacodynamics, clinical efficacy, and safety. Pharmacother J Hum Pharmacol Drug Ther 2014;34:1077-90.

24. Tourmousoglou CE, Rokkas CK. Clopidogrel and aspirin in cardiovascular medicine: responders or not--current best available evidence. Cardiovasc Hematol Agents Med Chem 2008;6:312-22.

25. Patil TR, Patil S, Patil A, Patil ST. Cardiovascular effects of proton pump inhibitors-a review. Int J Curr Pharm Rev Res 2016;7:198-203.

26. Yasmina A, de Boer A, Klungel OH, Deneer VH Pharmacogenomics of oral antiplatelet drugs. Pharmacogenomics 2014;15:509-28.

27. Husted S, van Giezen JJJ. Ticagrelor: the first reversibly binding oral P2Y 12 receptor antagonist. Cardiovasc Ther 2009;27:259-74.

28. Dhillon S. Ticagrelor: a review of its use in adults with acute coronary syndromes. Am J Cardiovasc Drugs 2015;15:51-68.

29. Teng R. Ticagrelor: pharmacokinetic, pharmacodynamic and pharmacogenetic profile: an update. Clin Pharmacokinet 2015;54:1125-38.

30. Lindholm D, Varenhorst C, Cannon CP, Harrington RA, Himmelmann A, Maya J, et al. Ticagrelor vs. clopidogrel in patients with non-ST-elevation acute coronary syndrome with or without revascularization: results from the PLATO trial. Eur Heart J 2014;35:2083-93.

31. Steg PG, James S, Harrington RA, Ardissino D, Becker RC, Cannon CP, et al. Ticagrelor versus clopidogrel in patients with st-elevation acute coronary syndromes intended for reperfusion with primary percutaneous coronary intervention: 
a platelet inhibition and patient outcomes (PLATO) trial subgroup analysis. Circulation 2010;122:2131-41.

32. Kang HJ, Clare RM, Gao R, Held C, Himmelmann A, James SK, et al. Ticagrelor versus clopidogrel in Asian patients with acute coronary syndrome: a retrospective analysis from the platelet inhibition and patient outcomes (PLATO) trial. Am Heart J 2015;169:899-905. e1.

33. Andersson C, Mérie C, Jørgensen M, Gislason GH, TorpPedersen C, Overgaard C, et al. Association of $\beta$-blocker therapy with risks of adverse cardiovascular events and deaths in patients with ischemic heart disease undergoing noncardiac surgery. JAMA Intern Med 2014;174:336.
34. Al-Gobari M, El Khatib C, Pillon F, Gueyffier F. Beta-blockers for the prevention of sudden cardiac death in heart failure patients: a meta-analysis of randomized controlled trials. BMC Cardiovasc Disord 2013;13:52.

\section{How to cite this article}

- Hendra Wana Nur'amin, Iwan Dwiprahasto, Erna Kristin. The effectiveness of ticagrelor compared to clopidogrel in reducing the risk of major adverse cardiovascular events in patients with coronary heart disease after percutaneous coronary intervention. Int J Pharm Pharm Sci 2017;9(9):178-183. 